\title{
Comparison of the Predictive Value of Antral Follicle Count, Anti-Müllerian Hormone and Follicle-Stimulating Hormone in Women Following GnRH-Antagonist Protocol for Intracytoplasmic Sperm Injection
}

\author{
Shahinaz H. El-Shorbagy \\ Departments of Obstetrics \& Gynecology, Faculty of Medicine, Tanta University, Tanta, Egypt \\ Email: Shahyshorbagy70@yahoo.com
}

How to cite this paper: El-Shorbagy, S.H. (2017) Comparison of the Predictive Value of Antral Follicle Count, Anti-Müllerian Hormone and Follicle-Stimulating Hormone in Women Following GnRH-Antagonist Protocol for Intracytoplasmic Sperm Injection. Open Journal of Obstetrics and Gynecology, 7, 432-446.

https://doi.org/10.4236/ojog.2017.74045

Received: March 17, 2017

Accepted: April 18, 2017

Published: April 21, 2017

Copyright $\odot 2017$ by author and Scientific Research Publishing Inc. This work is licensed under the Creative Commons Attribution International License (CC BY 4.0).

http://creativecommons.org/licenses/by/4.0/

\begin{abstract}
Background: Prediction of ovarian response is one of the prerequisites for women undergoing intracytoplasmic sperm injection (ICSI) treatment prior to the first controlled ovarian stimulation (COS) cycle. Predictive factors may be variable in patients pre-treated with oral contraceptives (OC) for scheduling purposes. Objective: To evaluate antral follicle count (AFC), anti-müllerian hormone (AMH) and basal follicle stimulating hormone (FSH) for predicting ovarian responses in patients under controlled ovarian hyperstimulation randomized to receive either oral contraceptives (OC) or no treatment (non-OC) prior to their first controlled ovarian stimulation (COS) cycle. Study Design: One hundred infertile women randomized to receive OC treatment or no treatment, prior to their first COS cycle; were stimulated with Gonadotropin Releasing Hormone (GnRH) antagonist protocol. During the early follicular phase (day 2) of the two subsequent cycles (cycle A \& cycle B) sonographic (AFC, ovarian volume) and endocrine data (AMH, basal FSH) were recorded. Transvaginal ultrasound was performed for all patients to monitor the ovarian response. Total number of oocytes retrieved and number of generated embryos were recorded and patients were categorized according to retrieved oocytes as poor (oocytes $<5$ ), normal (oocytes $5-12$ ) or high responders (oocytes $>12$ ). Result(s): AFC, AMH and basal FSH were lower in users than in non-users of hormonal contraception. Poor responders showed less number of oocytes retrieved and had lower AFC and AMH but a higher basal FSH level was recorded in both groups (OC and non-OC). Conclusion: The better predictive value of AMH or AFC, as a single test or in combination will prevent cycle cancellations due to too low or too high ovarian response.
\end{abstract}


$\mathrm{AMH}$ in OC group is not affected by OC pretreatment and is superior to other parameters, while AFC is superior to AMH and basal FSH in non-OC group.

\section{Keywords}

AFC, FSH, AMH, Ovarian Response, GnRH Antagonist

\section{Introduction}

One of the prerequisites for women undergoing intracytoplasmic sperm injection (ICSI) treatment is the fertility potential of women which is dependent on the quantity and the quality of the ovarian reserve (OR) [1].

The first indicator of the OR taken into consideration is the age of women. Although the number and quality of oocytes both decrease with age, the fertility potential varies drastically among women of similar age; so, they might exhibit different responses to ovarian stimulation [2].

An ideal marker for ovarian reserve is of enormous help to reproductive physicians in predicting the outcome of assisted reproductive technology (ART) as it involves huge costs and burden to the couples who seek treatment [3].

Haadsma et al. showed that among the various methodologies applied to maximize accuracy of OR determinations, none has been universally accepted as superior to others [4].

Follicle stimulating hormone (FSH) still represents the most widely utilized tool in routine daily practice [5] [6]. Anti-Müllerian hormone (AMH) measurement and antral follicle counts (AFC) have increasingly attracted researchers [4] [7].

The ovarian reserve is directly correlated with antral follicles in the early follicular phase. The decrease of AFC in basal ultrasound is a sign of ovarian aging, which is observed prior to an increase in FSH levels [8]. It was previously demonstrated that an AFC cut-off value of 3 to 7 indicates a significant decrease in ovarian reserve and subsequently poor ovarian response in in vitro fertilization (IVF) cycles [9].

Within the ovary, AMH is involved in the regulation of the number of primordial follicles that begin maturation, preventing premature exhaustion of the ovarian reserve. In granulosa cells, AMH is also involved in the regulation of steroidogenesis [10].

Maturation into small antral follicles is characterized by maximal expression and concentrations of AMH within the follicle, followed rapidly by diminishing expression of AMH and growing dependence on FSH, which promotes further development into large antral and then pre-ovulatory follicles [11]. Thus, AFC is strongly related to circulating AMH levels since the hormone is produced by antral follicles themselves [12].

A number of environmental and biological factors have been suggested to cause 
changes in ovarian reserve markers such as the continuous use of certain contraceptives and current cigarette smoking. Bentzen et al. detected that ovarian reserve markers were lower in women using oral contraception than controls [13].

The basis of ovarian stimulation for assisted reproduction treatment is the administration of exogenous gonadotropins, to permit retrieval of multiple oocytes during a single cycle. It is necessary to maintain FSH and luteinizing hormone (LH) concentrations above a critical threshold, so that multiple competent follicles are selected for growth and maturation. A gonadotrophin-releasing hormone agonist or antagonist is given concurrently to ensure prevention of a premature spike of LH that would induce ovulation [14]. Final oocyte maturation is then typically triggered by the administration of a bolus of human chorionic gonadotropin (HCG), which is structurally and biologically similar to $\mathrm{LH}$ and binds to the same LH/HCG receptor [15].

Wallace and Kelsey showed that indirect determination of ovarian reserve is important in the treatment of infertility, since there is no known method for assessing the ovarian reserve of individual women [16].

There are conflicting data regarding AFC compared to $\mathrm{AMH}$ in predicting ovarian response to gonadotropins in IVF cycles. Mutlu et al. showed on 192 infertile women referred for IVF therapy that sonographic evaluation of the AFC can predict ovarian response to gonadotropins better than hormonal indices of ovarian reserve (baseline AMH and baseline FSH) [17]. They added that patients could have pregnancies in the lower extremes of even $\mathrm{AMH}$, the most widely used hormonal test nowadays. Also, Tsakos et al. detected on 105 infertile women undergoing intracytoplasmic sperm injection (ICSI) that AFC, baseline $\mathrm{AMH}$ and baseline FSH are good predictors for the outcome of ovarian stimulation in Gonadotropin Releasing Hormone (GnRH) antagonist protocol [1]. They added that AFC appears to have the best predictive value.

Other previous studies have shown that both AFC and AMH have a similar predictive value [18] [19] [20]. On the other hand Ficicioglu et al. and Mcllveen et al. showed that $\mathrm{AMH}$ was better than $\mathrm{AFC}$ in predicting ovarian response to gonadotropins [21] [22].

The discrepancies between studies encourage me to do the present research to evaluate the prognostic ability of the antral follicle count, anti-Müllerian hormone and basal follicle stimulating hormone for predicting ovarian responses (the number of retrieved oocytes and the number of generated embryos by ICSI) to hyperstimulation using gonadotrophin-releasing hormone antagonist protocol, in women either pre-treated with oral contraceptives (OC) treatment; or received no treatment (non-OC) prior to their first controlled ovarian stimulation (COS) cycle to prevent cycle cancellations due to too low or too high ovarian response.

\section{Materials and methods}

\subsection{Patients}

The randomized controlled study was carried out on one hundred infertile 
women age ranged 22 - 40 years attending infertility outpatient clinic of Tanta University Hospital and private centers from August 2016 to February 2017 in Egypt. This study was conducted with the permission of Ethical Committee and the local regulatory authorities covering all participating study centers (31327/ 01/17). All patients signed a written consent after explanation of the nature of the study. The inclusion criteria were: age between 22 and 40 years; regular menstrual cycles (21 - 35 days); body mass index (BMI) $\leq 30 \mathrm{~kg} / \mathrm{m}^{2}$. The exclusion criteria were: endocrine disorders as abnormal thyroid function or hyperprolactinaemia; prior ovarian surgery; severe endometriosis; basal FSH or LH > $12 \mathrm{mIU} / \mathrm{ml}$ in early follicular phase; uterine fibroids $>5 \mathrm{~cm}$. The 100 chosen patients were randomized into two blocks each of 50 by random numbers in sealed envelopes opened by the ART nurse not involved in the present research. From every 50 randomized subjects, twenty five were allocated to receive OC treatment; while the other 25 received no treatment prior to their first COS cycle in a random manner.

\subsection{Methods}

\subsubsection{Predictive Factors Used}

Predictive factors, including demographic (age, BMI, duration of infertility) sonographic (AFC; ovarian volume) and endocrine factors $\{\mathrm{AMH}$, basal FSH; serum estradiol (E2) $\}$ were assessed in two subsequent cycles $(\mathrm{A}, \mathrm{B})$.

\subsubsection{Assessments of Ovarian Stimulation in OC and Non-OC Group}

In the OC group, these assessments were made on cycle A day 2 or 3 and at stimulation day 1 on cycle $B$ at least 4 days after the last OC pill intake.

In the non-OC assessments were made on cycle A day 2 or 3 and at stimulation day 1 on cycle B day 2 or 3. Ultrasound machine (Philips HD-3; Koninkijke Philips Electronics N.V.) was used for measuring all visible follicles less than 10 $\mathrm{mm}$ in diameter in both ovaries (AFC) and ovarian volume. AMH and basal FSH were measured on the same day in serum by immunoenzymatic assays.

The OC group received Yasmin (drospirenone/ethinyl estradiol) 21 active film coated tablets each containing $3 \mathrm{mg}$ of drospirenone and $0.03 \mathrm{mg}$ of ethinyl estradiol (EE) for 21 days and started daily recombinant follicle stimulating hormone $\{r F S H$ follitropin alfa (Gonal F Merk Serano Europe LTD, London, UK) 4 days after stopping OC treatment (stimulation day 1) if withdrawal bleeding had occurred, if not the start of stimulation was delayed till the beginning of full bleeding otherwise the patient was withdrawn from the study.

The non-OC group started daily $\mathrm{rFSH}$ (Gonal F) on stimulation day 1 cycle $\mathrm{B}$ (Day 2 or 3 of the next menstrual cycle). In both groups, a single subcutaneous injection of $225 \mathrm{IU}$ rFSH (Gonal F) was given on stimulation day 1 and continued daily up to and including the day of triggering of final oocyte maturation by urinary human chorionic gonadotrophin (hCG). According to ovarian response, assessed by ultrasound and serum E2 levels every 2 days, the dosage of $\mathrm{rFSH}$ (Gonal F) was adjusted. The maximum total stimulation period was 18 days. Starting on stimulation day 5 , all patients received continued $0.25 \mathrm{mg}$ cetrotide 
(Cetrorelix acetate Merk Serano Europe LTD, London, UK) daily injection under the skin of the lower abdomen throughout the ovarian stimulation period to prevent premature ovulation in women which can result in the release of immature eggs.

Oocyte retrieval was performed by an $8 \mathrm{MHz}$ transvaginal ultrasound 34 - 36 hours after hCG injection (10,000 IU) when two or more follicles $\geq 16$ were seen. Embryo transfer, 3 or 5 days after oocyte pick up, a maximum of three embryos were replaced under ultrasound guidance. Women of both groups received daily progesterone ( $\geq 800 \mathrm{mg} /$ day vaginally or $\geq 100 \mathrm{mg} /$ day intramuscularly) for $\geq 6$ weeks in case of pregnancy or until menses or up to a negative pregnancy test performed $\geq 14$ days after embryo transfer. Total number of follicles and oocytes retrieved were recorded and patients were categorized as poor (oocytes < 5), normal (oocytes 5 - 12) or high responders (oocytes $>12$ ). Correlation between cycles A and B was performed in the two groups (OC and non-OC).

\subsubsection{Outcome Measure}

The primary outcome measure was the number of generated embryos.

The secondary outcome measures were total number of oocytes retrieved correlated with AFC, AMH, FSH and E2 levels on the day of HCG injection.

\subsubsection{Statistical Analysis}

Statistical analysis was carried out using the software program SPSS for Windows, version 13.0 (SPSS, Chicago). Quantitative data were presented as mean and standard deviation. Student's t-test was used to compare means of predictive factors. Pearson correlation for measuring covariance of two variables divided by the product of their standard deviations measures the strength of a linear association between two variables and is denoted by $r$. The Receiver Operator Characteristic (ROC) curve was used to analyze the predictive accuracy of variables. AFC and AMH were used as variables in the analysis as determinants to predict ovulation response using Anova one way unstacked. Result was considered significant at a $\mathrm{P}$ value of $\leq 0.05$ and highly significant at a $\mathrm{P}$ value of $\mathrm{P}<0.01$.

\section{Results}

Our study included 100 randomized patients in the ART program; half of randomized patients received OC (Yasmin tablets) and the other randomized half received no treatment prior to their first COS cycle. The two treatment groups were similar with respect to mean age, BMI and duration of infertility (Table 1).

In the OC group sonographic and endocrine predictive factors were still slightly reduced when compared at stimulation day 1 with those at the start of OC pre-treatment. OC group showed highest correlation for AMH between cycles A and B. On the other hand a lower correlation was found for Total ovarian volume between cycles $\mathrm{A}$ and $\mathrm{B}$ in comparison with the non-OC group. For the non-OC group sonographic (AFC, ovarian volume) and endocrine (serum $\mathrm{AMH}$, basal FSH) predictive factors were comparable on the day of randomization (cycle A) and on stimulation day 1 (cycle B) showing highest correlation for 
Table 1. Demographic data of the studied groups.

\begin{tabular}{ccccc}
\hline Items & $\begin{array}{c}\text { OC } \\
(\mathrm{n}=5 \mathbf{5 0})\end{array}$ & $\begin{array}{c}\text { Non-OC } \\
(\mathrm{n}=5 \mathbf{5 0})\end{array}$ & $\begin{array}{c}\text { Total } \\
(\mathrm{n}=100)\end{array}$ & $\begin{array}{c}\text { P value } \\
\text { OC vs. Non-OC }\end{array}$ \\
\cline { 2 - 4 } & \multicolumn{3}{c}{ Mean $\pm \mathrm{SD}$} \\
\hline Age years & $30.18 \pm 5.24$ & $29.80 \pm 5.05$ & $29.99 \pm 5.12$ & 0.713 \\
BMI, kg/m ${ }^{2}$ & $26.54 \pm 1.98$ & $26.68 \pm 1.97$ & $26.61 \pm 1.96$ & 0.724 \\
Duration of infertility, years & $3.82 \pm 1.68$ & $3.68 \pm 1.60$ & $3.75 \pm 1.64$ & 0.672 \\
\hline
\end{tabular}

$\mathrm{BMI}=$ body mass index $\mathrm{OC}=$ Oral contraceptives; Non-OC $=$ Non-Oral contraceptives; vs. $=$ versus.

Table 2. Sonographic and endocrine data.

\begin{tabular}{ccccc}
\hline Items & $\begin{array}{c}\text { Cycle A, } \\
\text { median }\end{array}$ & $\begin{array}{c}\text { Cycle B, } \\
\text { median }\end{array}$ & $\begin{array}{c}\text { Inter-cycle } \\
\text { variations, (SD) }\end{array}$ & $\begin{array}{c}\text { Correlation, } \\
\mathrm{p}(95 \% \mathrm{Cl})\end{array}$ \\
\hline OC group & & & & \\
AFC & 6.5 & 6 & 4.5 & $0.64(0.51-0.84)$ \\
Total ovarian volume (ml) & 7.8 & 7.5 & 1.77 & $0.41(0.32-0.52)$ \\
Serum AMH (ng/ml) & 2.25 & 2.2 & 0.59 & $0.79(0.71-0.89)$ \\
Serum FSH (IU/l) & 6.2 & 6.4 & 1.85 & $0.61(0.54-0.67)$ \\
& & & & \\
Non-OC group & 5 & 7 & 12.70 & $0.66(0.58-0.79)$ \\
AFC & 7.4 & 7.7 & 1.54 & $0.49(0.42-0.57)$ \\
Total ovarian volume (ml) & 1.9 & 2.5 & 0.64 & $0.88(0.83-0.96)$ \\
Serum AMH (ng/ml) & 5.6 & 6.3 & 2.10 & $0.45(0.38-0.52)$ \\
Serum FSH (IU/l) & & & & \\
\hline
\end{tabular}

$\mathrm{OC}=$ Oral contraceptives; Non-OC $=$ Non-Oral contraceptives $; \mathrm{AFC}=$ antral follicle count $\mathrm{AMH}=$ anti-müllerian hormone; FSH = follicle-stimulating hormone.

$\mathrm{AMH}$, followed by the other predictor factors (Table 2).

Clinical outcomes, including the number of retrieved oocytes, the total number of embryos, serum E2 at day of HCG injection and total dose of stimulation in the two groups were presented in Table 3 . There was a significantly positive correlation between the number of oocytes as well as the number of embryos with $\mathrm{AMH}$ and $\mathrm{AFC}$ and a negative correlation between them and basal FSH in both OC and non-OC groups. Total dose of stimulation was significantly negatively correlated with AMH and AFC in both OC and non-OC groups. The strongest correlation was found with $\mathrm{AMH}$ in $\mathrm{OC}$ group and $\mathrm{AFC}$ in non-OC group.

In OC group, 15 women (30\%) had poor response (oocytes retrieved $<5$ ), 30 (60\%) had normal response (oocytes retrieved $<5-12$ ) and 5(10\%) had high response (oocytes retrieved $>12$ ). In non-OC group who received no treatment; 8 patients (16\%) had poor response, $35(70 \%)$ had normal response and $7(14 \%)$ had high response. Poor responders in IVF showed less number of oocytes retrieved and had lower AFC and AMH but higher basal FSH levels in both groups (OC and Non-OC).

There was no significant difference between poor, normal and high respond- 
Table 3. Correlation between number of retrieved oocytes, number of embryos, E2 at day of HCG injection, total dose of stimulation, basal FSH, AMH blood levels and AFC (cycle B).

\begin{tabular}{|c|c|c|c|c|}
\hline Items & & $\mathrm{AMH}$ & Basal FSH & AFC \\
\hline \multicolumn{5}{|l|}{ OC group } \\
\hline \multirow[t]{2}{*}{ Number of oocyte } & $\mathbf{r}$ & 0.522 & -0.325 & 0.489 \\
\hline & $\mathrm{p}$ & $0.001^{*}$ & $0.021^{*}$ & $0.001^{*}$ \\
\hline \multirow[t]{2}{*}{ Number of embryos } & $\mathbf{r}$ & 0.456 & -0.351 & 0.774 \\
\hline & $\mathrm{p}$ & $0.001^{*}$ & $0.012^{*}$ & $0.001^{\star}$ \\
\hline \multirow{2}{*}{ Serum $\mathrm{E}_{2}$ at day of $\mathrm{HCG}$ injection. } & $\mathbf{r}$ & 0.493 & -0.082 & 0.488 \\
\hline & $\mathrm{p}$ & $0.001^{*}$ & 0.569 & $0.001^{\star}$ \\
\hline \multirow[t]{2}{*}{ Total dose of stimulation } & $\mathbf{r}$ & -0.673 & 0.285 & -0.349 \\
\hline & $\mathrm{p}$ & $0.001^{*}$ & $0.045^{\star}$ & $0.013^{*}$ \\
\hline \multicolumn{5}{|l|}{ Non-OC group } \\
\hline \multirow[t]{2}{*}{ Number of oocyte } & $\mathbf{r}$ & 0.381 & -0.445 & 0.427 \\
\hline & $\mathrm{p}$ & $0.006^{*}$ & $0.016^{*}$ & $0.002^{*}$ \\
\hline \multirow[t]{2}{*}{ Number of embryos } & $\mathbf{r}$ & 0.563 & -0.413 & 0.390 \\
\hline & $\mathrm{p}$ & $0.015^{*}$ & $0.025^{*}$ & $0.035^{\star}$ \\
\hline \multirow[t]{2}{*}{ Serum $E_{2}$ at day of HCG injection. } & $\mathbf{r}$ & 0.179 & -0.307 & 0.427 \\
\hline & $\mathrm{p}$ & 0.215 & 0.058 & $0.002^{*}$ \\
\hline \multirow[t]{2}{*}{ Total dose of stimulation } & $\mathbf{r}$ & -0.406 & 0.486 & -0.310 \\
\hline & $\mathrm{p}$ & $0.025^{\star}$ & $0.012^{*}$ & $0.028^{*}$ \\
\hline
\end{tabular}

$\mathrm{OC}=$ Oral contraceptives; Non-OC = Non-Oral contraceptives; $\mathrm{AMH}=$ anti- müllerian hormone; FSH = follicle-stimulating hormone; $\mathrm{E}_{2}=$ estradiol; HCG = Human Chorionic Gonadotropin; ${ }^{*}$ = significant.

ers of both groups (OC and non-OC) regarding age, BMI and ovarian volume, but statistically significant differences were recorded among other predictive factors and clinical outcomes. There were a statistically significant decreased number of antral follicles, number of retrieved oocytes and number of embryos, serum AMH and estradiol at day of HCG injection in poor responders compared to normal and high responders. On the other hand, there was a statistically significant increase of basal FSH and total dose of stimulation, in poor responders compared to normal and high responders. Both AMH and FSH were highly significant factors in OC group and AFC in Non-OC group (Table 4 and Table 5).

Receiver-operation curve (ROC) analysis was performed for the groups of poor, normal and high responders including AMH, AFC and basal FSH in both OC and non-OC groups. The results of ROC analysis confirmed the prognostic value of these parameters in both groups regarding the number of retrieved oocytes with FSH and AMH superior to other parameters in OC group; while AFC is superior to other parameters in non-OC (Table 6).

\section{Discussion}

Predictive factors of ovarian response in assisted reproductive technology appeared to be vital for the counseling and management of women in clinical prac- 
tice as well as to determine the best $\mathrm{rFSH}$-starting dose [23] or the best treatment regimen, i.e. GnRH antagonist versus long GnRH agonist protocol [24] Some women respond poorly to ovarian stimulation, e.g. development of less than four retrieved oocytes [25], and others may experience a hyper-response, e.g. development of over 15 retrieved oocytes [26]. Early identification of potential low and high responders is relevant to enable individualization of the ovarian stimulation treatment regimen [27].

Table 4. Comparison between poor responders, normal and high responders regarding demographic data and hormones in OC group (cycle B).

\begin{tabular}{|c|c|c|c|c|c|}
\hline \multirow[t]{2}{*}{ Items } & $\begin{array}{c}\text { OC } \\
(n=50)\end{array}$ & $\begin{array}{l}\text { Poor responders } \\
\qquad(\mathrm{n}=15)\end{array}$ & $\begin{array}{l}\text { Normal responders } \\
\qquad(\mathrm{n}=30)\end{array}$ & $\begin{array}{l}\text { High responders } \\
\qquad(\mathrm{n}=5)\end{array}$ & \multirow[t]{2}{*}{$P$ value } \\
\hline & \multicolumn{4}{|c|}{ Mean \pm SD } & \\
\hline Age years & $30.18 \pm 5.24$ & $31.46 \pm 5.05$ & $30.03 \pm 5.45$ & $27.20 \pm 3.70$ & $0.286(\mathrm{NS})$ \\
\hline BMI, $\mathrm{kg} / \mathrm{m}^{2}$ & $26.54 \pm 1.98$ & $27.26 \pm 2.21$ & $26.16 \pm 1.74$ & $26.60 \pm 2.40$ & $0.217(\mathrm{NS})$ \\
\hline AFC & $6.52 \pm 2.51$ & $4.20 \pm 0.56$ & $6.63 \pm 0.89$ & $12.80 \pm 1.09$ & 0.000 (HS) \\
\hline Total ovarian volume (ml) & $7.66 \pm 1.32$ & $7.07 \pm 1.19$ & $7.82 \pm 1.32$ & $8.48 \pm 1.11$ & 0.067 (NS) \\
\hline Serum AMH (ng/ml) & $2.19 \pm 0.81$ & $1.64 \pm 0.52$ & $2.28 \pm 0.73$ & $3.32 \pm 0.67$ & 0.000 (HS) \\
\hline Serum FSH (IU/l) & $6.34 \pm 1.25$ & $7.16 \pm 1.05$ & $6.09 \pm 1.18$ & $5.36 \pm 0.96$ & 0.003 (HS) \\
\hline $\begin{array}{c}\text { Serum } \mathrm{E}_{2}(\mathrm{pg} / \mathrm{ml}) \text { at day of } \\
\text { HCG injection }\end{array}$ & $2090 \pm 1093$ & $1479 \pm 959$ & $2227 \pm 978$ & $3100 \pm 1294$ & 0.007 (HS) \\
\hline Number of oocytes & $6.72 \pm 3.68$ & $2.40 \pm 1.12$ & $7.83 \pm 2.06$ & $14.60 \pm 1.67$ & 0.000 (HS) \\
\hline Number of embryos & $5.36 \pm 2.40$ & $1.86 \pm 0.83$ & $4.86 \pm 1.33$ & $5.60 \pm 1.51$ & 0.000 (HS) \\
\hline Total dose of stimulation & $2752.4 \pm 866.3$ & $3380.5 \pm 962.3$ & $2515.7 \pm 696.4$ & $2344.8 \pm 482.8$ & 0.002 (HS) \\
\hline
\end{tabular}

$\mathrm{OC}=$ Oral contraceptives; $\mathrm{BMI}=$ body mass index; $\mathrm{AFC}=$ antral follicle count; $\mathrm{AMH}=$ anti-müllerian hormone; $\mathrm{FSH}=$ follicle-stimulating hormone; $\mathrm{E}_{2}=$ estradiol.; HCG = Human Chorionic Gonadotropin; NS = non-significant; HS = highly significant.

Table 5. Comparison between poor responders, normal and high responders regarding demographic data and hormones in Non-OC group.

\begin{tabular}{|c|c|c|c|c|c|}
\hline \multirow[t]{2}{*}{ Items } & $\begin{array}{l}\text { Non-OC } \\
(n=50)\end{array}$ & $\begin{array}{l}\text { Poor responders } \\
\qquad(\mathrm{n}=8)\end{array}$ & $\begin{array}{l}\text { Normal responders } \\
\quad(n=35)\end{array}$ & $\begin{array}{l}\text { High responders } \\
\qquad(\mathrm{n}=7)\end{array}$ & \multirow[t]{2}{*}{$P$ value } \\
\hline & \multicolumn{4}{|c|}{ Mean \pm SD } & \\
\hline Age years & $29.80 \pm 5.05$ & $31.25 \pm 1.66$ & $30.08 \pm 5.64$ & $26.71 \pm 3.14$ & $0.186(\mathrm{NS})$ \\
\hline BMI, $\mathrm{kg} / \mathrm{m}^{2}$ & $26.68 \pm 1.97$ & $27.75 \pm 1.98$ & $26.54 \pm 1.90$ & $26.14 \pm 2.19$ & $0.222(\mathrm{NS})$ \\
\hline AFC & $7.84 \pm 4.28$ & $3.50 \pm 1.10$ & $7.57 \pm 3.22$ & $14.14 \pm 4.22$ & $0.000(\mathrm{HS})$ \\
\hline Total ovarian volume $(\mathrm{ml})$ & $7.74 \pm 1.26$ & $7.33 \pm 1.28$ & $7.72 \pm 1.30$ & $8.31 \pm 0.99$ & $0.331(\mathrm{NS})$ \\
\hline Serum AMH (ng/ml) & $2.46 \pm 0.81$ & $1.86 \pm 0.79$ & $2.45 \pm 0.66$ & $3.21 \pm 1.03$ & $0.004(\mathrm{HS})$ \\
\hline Serum FSH (IU/l) & $6.27 \pm 1.65$ & $7.30 \pm 1.53$ & $5.96 \pm 1.61$ & $6.97 \pm 1.27$ & $0.054(S)$ \\
\hline Serum $E_{2}(\mathrm{pg} / \mathrm{ml})$ & $2159.9 \pm 1071.1$ & $907.2 \pm 524.1$ & $2271.7 \pm 925.2$ & $3032.4 \pm 1069.7$ & $0.000(\mathrm{HS})$ \\
\hline Number of oocytes & $7.50 \pm 3.99$ & $2.50 \pm 1.19$ & $7.22 \pm 2.46$ & $14.57 \pm 1.39$ & $0.000(\mathrm{HS})$ \\
\hline Number of embryos & $6.02 \pm 2.21$ & $3.62 \pm 0.91$ & $6.65 \pm 2.24$ & $10.71 \pm 3.20$ & $0.000(\mathrm{HS})$ \\
\hline Total dose of stimulation & $2290.9 \pm 713.0$ & $3072.3 \pm 958.7$ & $2191.0 \pm 507.0$ & $1897.1 \pm 754.8$ & $0.001(\mathrm{HS})$ \\
\hline
\end{tabular}

$\mathrm{BMI}=$ body mass index; $\mathrm{AFC}=$ antral follicle count; $\mathrm{AMH}=$ anti-müllerian hormone; $\mathrm{FSH}=$ follicle-stimulating hormone; $\mathrm{E}_{2}=$ estradiol; Non-OC =Oral contraceptives; NS = non-significant; $\mathrm{S}=$ significant; $\mathrm{HS}$ = highly significant. 
Table 6. ROC analysis for the evaluation of prognostic value of AMH, AFC and basal FSH on the number of retrieved oocytes.

\begin{tabular}{|c|c|c|c|c|}
\hline \multirow{2}{*}{ Items } & \multirow{2}{*}{$\begin{array}{c}\text { Area under } \\
\text { the curve (AUC) }\end{array}$} & \multirow{2}{*}{ Significance $(P)$} & \multicolumn{2}{|c|}{$\begin{array}{l}\text { Asymptotic } 95 \% \mathrm{CI} \\
\text { Confidence Interval }\end{array}$} \\
\hline & & & Lower bound & Upper bound \\
\hline \multicolumn{5}{|l|}{ OC } \\
\hline \multicolumn{5}{|c|}{ Poor responders } \\
\hline $\mathrm{AMH}$ & 0.480 & 0.042 & 0.354 & 0.614 \\
\hline AFC & 0.920 & 0.028 & 0.730 & 0.997 \\
\hline FSH & 0.859 & 0.009 & 0.842 & 0.894 \\
\hline \multicolumn{5}{|c|}{ High responders } \\
\hline $\mathrm{AMH}$ & 0.875 & 0.009 & 0.741 & 0.924 \\
\hline AFC & 0.780 & 0.035 & 0.605 & 0.865 \\
\hline FSH & 0.785 & 0.009 & 0.584 & 0.854 \\
\hline \multicolumn{5}{|c|}{ Non-OC } \\
\hline \multicolumn{5}{|c|}{ Poor responders } \\
\hline AMH & 0.733 & 0.043 & 0.621 & 0.944 \\
\hline AFC & 0.658 & 0.002 & 0.584 & 0.875 \\
\hline FSH & 0.595 & 0.039 & 0.515 & 0.705 \\
\hline \multicolumn{5}{|c|}{ High responders } \\
\hline $\mathrm{AMH}$ & 0.945 & 0.002 & 0.859 & 0.997 \\
\hline $\mathrm{AFC}$ & 0.935 & 0.002 & 0.875 & 0.981 \\
\hline FSH & 0.669 & 0.047 & 0.540 & 0.799 \\
\hline
\end{tabular}

$\mathrm{OC}=$ Oral contraceptives; $\mathrm{AMH}=$ anti-müllerian hormone; $\mathrm{AFC}=$ antral follicle count; $\mathrm{FSH}=$ follicle-stimulating hormone.

Markers of ovarian reserve are regularly used to predict poor ovarian response to gonadotrophin stimulation which is suspected in the presence of high levels of FSH and/or estradiol, or more recently on the basis of a low AFC or reduced levels of AMH [28].

Oral contraceptives used before assisted reproductive technology cycles may influence some of the ovarian predictor factors. For this reason, this study aims to determine the value of AFC, AMH and basal FSH to predict ovarian response in a group of patients undergoing hyperstimulation using gonadotrophin-releasing hormone antagonist protocol, in women either pre-treated with oral contraceptives treatment; or received no treatment prior to their first COS cycle.

The present study includes 100 women; half of them received OC, and the other half received no treatment prior to their first COS cycle. There was no significant difference between poor responders, normal and high responders regarding age, BMI and duration of infertility in both studied groups. Such findings coincided with those of Andersen et al, who showed that OC and non-OC were similar with respect to mean age, BMI and duration of infertility [29]. Hendriks et al. concluded that age cannot be taken as a sole predictor of cumulative pregnancy to identify poor prognosis cases [30]. However, unlike our re- 
sults, Vural et al. found that age was significantly higher in the poor responder group [31]. The age-related decline in female fertility is most likely due to the decline in both the quantity and quality of oocytes. As a result of diminished ovarian reserve, the ability of women to conceive naturally is restricted after the age of 40 [17]. The difference from our result may be attributed to the small sample size and the fact that our patients had a narrow age range with older patient aged 40 years according to inclusion criteria.

Similar to our results, Maheshwar et al. reported that the number of follicles resulting from IVF is not different in underweight, overweight and obese patients when compared with women with normal BMI [32]. However, optimal body weight is very important for the healthy continuity of women reproductive functions. Rich-Edwards et al. found that overweight and morbid obesity is associated with anovulatuar infertility [33].

Poor responders in the present study showed less number of oocytes retrieved and had lower AFC and AMH but higher basal FSH levels in both studied groups. There was significantly positive correlation between the number of oocytes as well as the number of embryos with AMH and AFC and a negative correlation between them and basal FSH in both OC and non-OC groups. Total dose of stimulation was significantly negatively correlated with AMH and AFC in both $\mathrm{OC}$ and non-OC groups. The strongest correlation was found with $\mathrm{AMH}$ in OC group and AFC in non-OC group.

Similar to our results, Vural et al. and, Jaiswar et al. found that AFC was significantly lower in the poor responder group [31] [34]. In the past Chang et al and Frattarelli et al. found that AFC correlates with the number of mature oocytes and ART outcomes [35] [36]. Also, AFC is strongly related to circulating AMH levels since the hormone is produced by antral follicles themselves [12].

Regarding AMH, Fiçicioglu et al found that the mean serum AMH levels of patients with more than five retrieved oocytes were found to be higher than poor responders [21]. Also, Elgindy et al. and Tanriverdi et al. found lower serum AMH levels in poor ovarian responders than in normal responders [37] [38].

Several studies have emphasized that $\mathrm{AMH}$ could be a strong indicator for determining the ovarian response. Choi et al. found a close correlation between the retrieved oocyte number and AMH levels [39]. They also reported a significantly decreased cutoff value for the serum AMH levels of poor responder patients.

Prediction of response to ovarian stimulation with gonadotropins before IVF treatment could help clinicians to establish an optimal treatment strategy and prevent cycle cancellations for poor responders.

In the present study both AFC and AMH were the most significant predictors of poor ovarian response and their predictive accuracy was nearly similar. Our results were similar to those of Lee et al. who found that both serum AMH and $\mathrm{AFC}$ were reliable ovarian reserve markers for predicting poor and high ovarian response [40].

Our results showed that the strongest correlation was found with AMH in OC 
group and AFC in non-OC group. Such finding coincided with many researchers. Fiçicioglu et al. and Mcllveen et al. found that AMH is being a better predictor than AFC and other hormonal markers [21] [22]. The reason is that there is considerable variability in the clinical definition and technical methodology used to count and measure follicles in both published studies and clinical practice [41]. The better performance of AMH over AFC in these trials can be explained by the considerable sonographer-dependent variability across centers. $\mathrm{AMH}$ levels remain unmodified due to OC pre-treatment as previously described for pituitary-suppressed patients using GnRH analogues or OC [10].

However other studies found that AFC is significantly better than AMH as predictors of poor ovarian response [42].

The physician variability between different IVF clinics may also explain the different performance of AFC in single-center and multicenter studies. While, AFC helps to establish follicle sizes and evaluate size discrepancies, AMH provides information essentially on the number of very small, non-atretic follicles, thus both analyses being complementary to the proper adaptation of the type of stimulation required by the patient [43].

The maximum number of oocytes that could be retrieved in women is strongly limited by the number of recruitable antral follicles in the ovaries and it is obvious that a gonadotrophin dose higher than the maximum will never compensate for the lack of substrate [44]. A large body of evidence clearly indicates that $\mathrm{AMH}$ and AFC may be considered interchangeable and globally perform better than all other known markers of ovarian response in IVF [45].

\section{Conclusion}

In conclusion the better predictive value of $\mathrm{AMH}$ or $\mathrm{AFC}$, as a single test or in combination will prevent cycle cancellations due to too low or too high ovarian response and reduce the risk of ovarian hyperstimulation syndrome (OHSS). Therefore it is recommended to include both AFC and AMH in routine evaluation of infertile couples undergoing IVF trial.

\section{References}

[1] Tsakos, E., Tolikas, A., Daniilidis, A. and Asimakopoulos, B. (2014) Predictive Value of Anti-Müllerian Hormone, Follicle-Stimulating Hormone and Antral Follicle Count on the Outcome of Ovarian Stimulation in Women Following GnRH-Antagonist Protocol for IVF/ET. Archives of Gynecology and Obstetrics, 290, 12491253. https://doi.org/10.1007/s00404-014-3332-3

[2] Fauser, B.C., Diedrich, K. and Devroey, P. (2008) Predictors of Ovarian Response: Progress towards Individualized Treatment in Ovulation Induction and Ovarian Stimulation. Human Reproduction Update, 14, 1-14. https://doi.org/10.1093/humupd/dmm034

[3] Aflatoonian, A., Oskouian, H., Ahmadi, S. and Oskouian, L. (2009) Prediction of High Ovarian Response to Controlled Ovarian Hyperstimulation: Anti-Müllerian Hormone versus Small Antral Follicle Count (2 - $6 \mathrm{~mm}$ ). Journal of Assisted Reproduction and Genetics, 26, 319-325. https://doi.org/10.1007/s10815-009-9319-5

[4] Haadsma, M.L., Groen, H., Fidler, V., Bukman, A., Roeloffzen, E.M., Groenewoud, 
E.R., Broekmans, F.J., Heineman, M.J. and Hoek, A. (2008) The Predictive Value of Ovarian Reserve Tests for Spontaneous Pregnancy in Subfertile Ovulatory Women. Human Reproduction, 23, 1800-1807. https://doi.org/10.1093/humrep/den234

[5] Singer, T., Barad, D.H., Weghofer, A. and Gleicher, N. (2009) Correlation of Antimüllerian Hormone and Baseline Follicle-Stimulating Hormone Levels. Fertility and Sterility, 91, 2616-2619. https://doi.org/10.1016/j.fertnstert.2008.03.034

[6] Barad, D.H., Weghofer, A. and Gleicher, N. (2009) Comparing Anti-Müllerian Hormone (AMH) and Follicle-Stimulating Hormone (FSH) as Predictors of Ovarian Function. Fertility and Sterility, 91, 1553-1555.

https://doi.org/10.1016/j.fertnstert.2008.09.069

[7] van Disseldorp, J., Lambalk, C.B., Kwee, J., Looman, C.W., Eijkemans, M.J., Fauser, B.C. and Broekmans, F.J. (2010) Comparison of Inter- and Intra-Cycle Variability of Anti-Müllerian Hormone and Antral Follicle Counts. Human Reproduction, 25, 221-227. https://doi.org/10.1093/humrep/dep366

[8] Bancsi, L.F., Broekmans, F.J., Eijkemans, M.J., de Jong, F.H., Habbema, J.D. and Te Velde, E.R. (2002) Predictors of Poor Ovarian Response in In Vitro Fertilization: A Prospective Study Comparing Basal Markers of Ovarian Reserve. Fertility and Sterility, 77, 328-336. https://doi.org/10.1016/S0015-0282(01)02983-1

[9] Scheffer, G.J., Broekmans, F.J., Dorland, M., Habbema, J.D., Looman, C.W. and Te Velde, E.R. (1999) Antral Follicle Counts by Transvaginal Ultrasonography Are Related to Age in Women with Proven Natural Fertility. Fertility and Sterility, 72, 845-851. https://doi.org/10.1016/S0015-0282(99)00396-9

[10] La Marca, A., Broekmans, F.J., Volpe, A., Fauser, B.C. and Macklon, N.S. (2009) Anti-Müllerian Hormone (AMH): What Do We Still Need to Know? Human Reproduction, 24, 2264-2275. https://doi.org/10.1093/humrep/dep210

[11] Baerwald, A.R., Adams, G. and Pierson, R.A. (2012) Ovarian Antral Folliculogenesis during the Human Menstrual Cycle. Human Reproduction Update, 18, 73-91. https://doi.org/10.1093/humupd/dmr039

[12] Weenen, C., Laven, J.S., Von Bergh, A.R., Cranfield, M., Groome, N.P., Visser, J.A., Kramer, P., Fauser, B.C. and Themmen, A. (2004) Anti-Müllerian Hormone Expression Pattern in the Human Ovary: Potential Implications for Initial and Cyclic Follicle Recruitment. Molecular Human Reproduction, 10, 77-83. https://doi.org/10.1093/molehr/gah015

[13] Bentzen, J.G., Forman, J.L., Pinborg, A., Lidegaard, Ø., Larsen, E.C., Friis-Hansen, L., Johannsen, T.H. and Nyboe Anderson, A. (2012) Ovarian Reserve Parameters: A Comparison between Users and Nonusers of Hormonal Contraception. Reproductive Biomedicine Online, 25, 612-619. https://doi.org/10.1016/j.rbmo.2012.09.001

[14] Mochtar, M.H., Van der Veen Ziech, M. and van Wely, M. (2007) Recombinant Luteinizing Hormone (rLH) for Controlled Ovarian Hyperstimulation in Assisted Reproductive Cycles. Cochrane Database Systematic Review, 2, CD005070. https://doi.org/10.1002/14651858.cd005070.pub2

[15] Humaidan, P., Bodri, D., Papanikolaou, E.G. and Kol, S. (2012) HCG: Is It the Best Choice for Ovulation Triggering? Open Reproduction Science, 4, 1-3.

https://doi.org/10.2174/1874255601204010001

[16] Wallace, W.H.B. and Kelsey, T.W. (2010) Human Ovarian Reserve from Conception to the Menopause. PLoS ONE, 5, e8772.

https://doi.org/10.1371/journal.pone.0008772

[17] Mutlu, M.F., Erdem, M., Erdem, A., Yildiz, S., Mutlu, I., Arisoy, O. and Oktem, M. (2013) Antral Follicle Count Determines Poor Ovarian Response Better than antiMüllerian Hormone but Age Is the Only Predictor for Live Birth in In Vitro Fertili- 
zation Cycles. Journal of Assisted Reproduction and Genetics, 30, 657-665. https://doi.org/10.1007/s10815-013-9975-3

[18] Jayaprakasan, K., Campbell, B., Hopkisson, J., Johnson, I. and Raine- Fenning, N. (2010) A Prospective, Comparative Analysis of Anti-Müllerian Hormone, Inhibin-B, and Three-Dimensional Ultrasound Determinants of Ovarian Reserve in the Prediction of Poor Response to Controlled Ovarian Stimulation. Fertility and Sterility, 93, 855-864. https://doi.org/10.1016/j.fertnstert.2008.10.042

[19] Broer, S.L., Dolleman, M., Opmeer, B.C., Fauser, B.C., Mol, B.W. and Broekmans, F.J. (2011) AMH and AFC as Predictors of Excessive Response in Controlled Ovarian Hyperstimulation: A Meta-Analysis. Human Reproduction Update, 17, 46-54. https://doi.org/10.1093/humupd/dmq034

[20] Broer, S.L., van Disseldorp, J., Broeze, K.A., Dolleman, M., Opmeer, B.C., Bossuyt, P., et al. (2013) Added Value of Ovarian Reserve Testing on Patient Characteristics in the Prediction of Ovarian Response and Ongoing Pregnancy: An Individual Patient Data Approach. Human Reproduction Update, 19, 26-36.

https://doi.org/10.1093/humupd/dms041

[21] Fiçicioglu, C., Kutlu, T., Baglam, E. and Bakacak, Z. (2006) Early Follicular Antimüllerian Hormone as an Indicator of Ovarian Reserve. Fertility and Sterility, 85, 592-596. https://doi.org/10.1016/j.fertnstert.2005.09.019

[22] Mcllveen, M., Skull, J.D. and Ledger, W.L. (2007) Evaluation of the Utility of Multiple Endocrine and Ultrasound Measures of Ovarian Reserve in the Prediction of Cycle Cancellation in a High-Risk IVF Population. Human Reproduction, 22, 778785. https://doi.org/10.1093/humrep/del435

[23] Olivennes, F., Howles, C.M., Borini, A., Germond, M., Trew, G., Wikland, M., Zegers-Hochschild, F., Saunders, H. and Alam, V. (2009) Individualizing FSH Dose for Assisted Reproduction Using a Novel Algorithm: The CONSORT Study. Reproductive BioMedicine Online, 18, 195-204. https://doi.org/10.1016/S1472-6483(10)60256-8

[24] Nelson, S.M., Yates, R.W., Lyall, H., Jamieson, M., Traynor, I., Gaudoin, M., Mitchell, .P, Ambrose, P. and Fleming, R. (2009) Anti-Müllerian Hormone-Based Approach to Controlled Ovarian Stimulation for Assisted Conception. Human Reproduction, 24, 867-875. https://doi.org/10.1093/humrep/den480

[25] Hendriks, D.J., Mol, B.W., Bancsi, L.F., Te Velde, E.R. and Broekmans, F.J. (2005) Antral Follicle Count in the Prediction of Poor Ovarian Response and Pregnancy after In Vitro Fertilization: A Meta-Analysis and Comparison with Basal Follicle-Stimulating Hormone Level. Fertility and Sterility, 83, 291-301. https://doi.org/10.1016/j.fertnstert.2004.10.011

[26] Steward, R.G., Lan, L., Shah, A.A., Yeh, J.S., Price, T.M., Goldfarb, J.M. and Muasher, S.J. (2014) Oocyte Number as a Predictor for Ovarian Hyper-Stimulation Syndrome and Live Birth: An Analysis of 256,381 in Vitro Fertilization Cycles. Fertility and Sterility, 101, 967-973. https://doi.org/10.1016/j.fertnstert.2013.12.026

[27] Oehninger, S., Nelson, S.M., Verweij, P. and Stegmann, B.J. (2015) Predictive Factors for Ovarian Response in a Corifollitropin alfa/GnRH Antagonist Protocol for Controlled Ovarian Stimulation in IVF/ICSI Cycles. Reproductive Biology and Endocrinology, 13, 117. https://doi.org/10.1186/s12958-015-0113-1

[28] Nelson, S.M., Klein, B.M. and Arce, J.C. (2015) Comparison of Antimüllerian Hormone Levels and Antral Follicle Count as Predictor of Ovarian Response to Controlled Ovarian Stimulation in Good-Prognosis Patients at Individual Fertility Clinics in Two Multicenter Trials. Fertility and Sterility, 103, 923-930.

https://doi.org/10.1016/j.fertnstert.2014.12.114 
[29] Andersen, A.N., Witjes, H., Gordon, K. and Mannaerts, B., on behalf of the Xpect investigators (2011) Predictive Factors of Ovarian Response and Clinical Outcome after IVF/ICSI Following a rFSH/GnRH Antagonist Protocol with or without Oral Contraceptive Pre-Treatment. Human Reproduction, 26, 3413-3423. https://doi.org/10.1093/humrep/der318

[30] Hendriks, D.J., te Velde, E.R., Looman, C.W., Bancsi, L.F. and Broekmans, F.J. (2008) Expected Poor Ovarian Response in Predicting Cumulative Pregnancy Rates: A Powerful Tool. Reproductive Biomedicine Online, 17, 727-736. https://doi.org/10.1016/S1472-6483(10)60323-9

[31] Vural, B., Cakiroglu, Y., Vural, F. and Filiz, S. (2014) Hormonal and Functional Biomarkers in Ovarian Response. Archives of Gynecology and Obstetrics, 289, 1355-1361. https://doi.org/10.1007/s00404-013-3132-1

[32] Maheshwari, A., Scotland, G., Bell, J., McTavish, A., Hamilton, M. and Bhattacharya, S. (2009) The Direct Health Services Costs of Providing Assisted Reproduction Services in Overweight or Obese Women: A Retrospective Cross-Sectional Analysis. Human Reproduction, 24, 633-639. https://doi.org/10.1093/humrep/den424

[33] Rich-Edwards, J.W., Spiegelman, D., Garland, M., Hertzmark, E., Hunter, D.J., Colditz, G.A., Willett, W.C., Wand, H. and Manson, J.E. (2002) Physical Activity, Body Mass Index, and Ovulatory Disorder Infertility. Epidemiology, 13, 184-190. https://doi.org/10.1097/00001648-200203000-00013

[34] Jaiswar, S.P., Natu, S.M., Sujata, Sankhwar, P.L. and Manjari, G. (2015) Prediction of Poor Ovarian Response by Biochemical and Biophysical Markers: A Logistic Regression Model. The Journal of Obstetrics and Gynecology of India, 65, 411-416. https://doi.org/10.1007/s13224-014-0639-8

[35] Chang, M.Y., Chiang, C.H., Hsieh, T.T., Soong, Y.K. and Hsu, K.H. (1998) Use of the Antral Follicle Count to Predict the Outcome of Assisted Reproductive Technologies. Fertility and Sterility, 69, 505-510. https://doi.org/10.1016/S0015-0282(97)00557-8

[36] Frattarelli, J.L., Levi, A.J., Miller, B.T. and Segars, J.H. (2003) A Prospective Assessment of the Predictive Value of Basal Antral Follicles in In Vitro Fertilization Cycles. Fertility and Sterility, 80, 350-355.

https://doi.org/10.1016/S0015-0282(03)00664-2

[37] Elgindy, E.A., El-Haieg, D. and El-Sebaey, A. (2008) Anti-Müllerian Hormone: Correlation of Early Follicular, Ovulatory and Midluteal Levels with Ovarian Response and Cycle Outcome in Intracytoplasmic Sperm Injection Patients. Fertility and Sterility, 89, 1670-1676. https://doi.org/10.1016/j.fertnstert.2007.05.040

[38] Tanriverdi, G., Denir, S. and Ayla, S. (2013) Notch Signaling Pathway in Cumulus Cells Can Be a Novel Marker to Identify Poor and Normal Responder IVF Patients. Journal of Assisted Reproduction and Genetics, 30, 1319-1326. https://doi.org/10.1007/s10815-013-0072-4

[39] Choi, M.H., Yoo, J.H., Kim, H.O., Cha, S.H., Park, C.W. and Yang, K.M. (2011) Serum Anti-Müllerian Hormone Levels as a Predictor of the Ovarian Response and IVF Outcomes. Clinical Experimental Reproduction Medicine, 38, 153-158. https://doi.org/10.5653/cerm.2011.38.3.153

[40] Lee, M.H., Tar, C.A., Siew, C.H., Shaw, N.L., Stephanie, M.C. and Su, L.Y. (2014) Basal Serum Anti-Müllerian Hormone and Antral Follicle Count Are Predictors of Ovarian Response for Asian Women in Singapore. Asian Pacific Journal of Reproduction, 3, 169-175.

[41] Laven, J.S., Mulders, A.G., Visser, J.A., Themmen, A.P., de Jong, F.H. and Fauser, 
B.C. (2004) Anti-Müllerian Hormone Serum Concentrations in Normoovulatory and Anovulatory Women of Reproductive Age. The Journal of Clinical Endocrinology and Metabolism, 89, 318-323. https://doi.org/10.1210/jc.2003-030932

[42] Mehmet, F.M., Mehmet, E., Ahmet, E., Sule, Y., Ilknur, M., Ozgur, A. and Mesut, O. (2013) Antral Follicle Count Determines Poor Ovarian Response Better than AntiMüllerian Hormone but Age Is the Only Predictor for Live Birth in In Vitro Fertilization Cycles. Journal of Assisted Reproduction and Genetics, 30, 657-665. https://doi.org/10.1007/s10815-013-9975-3

[43] Dewailly, D., Andersen, C.Y., Balen, A., Broekmans, F., Dilaver, N., Fanchin, R., Griesinger, G., Kelsey, T.W., La Marca, A., Lambalk, C., Mason, H., Nelson, S.M., Visser, J.A., Wallace, W.H. and Anderson, R.A. (2014) The Physiology and Clinical Utility of Anti-Müllerian Hormone in Women. Human Reproduction Update, 20, 370-385. https://doi.org/10.1093/humupd/dmt062

[44] Lekamge, D.N., Barry, M., Kolo, M., Lane, M., Gilchrist, R.B. and Tremellen, K.P. (2007) Anti-Müllerian Hormone as a Predictor of IVF Outcome. Reproductive BioMedicine Online, 14, 602-610. https://doi.org/10.1016/S1472-6483(10)61053-X

[45] Lekamge, D.N., Lane, M., Gilchrist, R.B. and Tremellen, K.P. (2008) Increased Gonadotrophin Stimulation Does Not Improve IVF Outcomes in Patients with Predicted Poor Ovarian Reserve. Journal of Assisted Reproduction and Genetics, 25, 515-521. https://doi.org/10.1007/s10815-008-9266-6

\section{Submit or recommend next manuscript to SCIRP and we will provide best service for you:}

Accepting pre-submission inquiries through Email, Facebook, LinkedIn, Twitter, etc. A wide selection of journals (inclusive of 9 subjects, more than 200 journals) Providing 24-hour high-quality service

User-friendly online submission system

Fair and swift peer-review system

Efficient typesetting and proofreading procedure

Display of the result of downloads and visits, as well as the number of cited articles Maximum dissemination of your research work

Submit your manuscript at: http://papersubmission.scirp.org/

Or contact ojog@scirp.org 